\title{
Effect of adult leader participation on physical activity in children
}

\author{
Tanis J. Hastmann ${ }^{1^{*}}$, Karla E. Foster ${ }^{2}$, Richard R. Rosenkranz ${ }^{3}$, Sara K. Rosenkranz ${ }^{3}$, \\ David A. Dzewaltowski ${ }^{4}$ \\ ${ }^{1}$ Department of Physical Education, Exercise Science \& Wellness, University of North Dakota, Grand Forks, USA; \\ *Corresponding Author: tanis.hastmann@,und.edu \\ ${ }^{2}$ Cincinnati Children's Hospital Medical Center, Cincinnati, USA \\ ${ }^{3}$ Department of Human Nutrition, Kansas State University, Manhattan, USA \\ ${ }^{4}$ Department of Kinesiology, Kansas State University, Manhattan, USA
}

Received 10 August 2012; revised 15 September 2012; accepted 3 October 2012

\section{ABSTRACT}

Background: Participation in physically active games is one way to increase energy expendture in children. However, it is unknown whether adult leader participation (LP) in games can impact children's physical activity (PA) levels. The purpose of this study was to examine the influence of LP compared to no LP on PA levels among children participating in organized active games. Methods: Children $(n=14)$ in grades $4-6$ (Male $=42.8 \%$, White $=50 \%$, Overweight $/$ Obese $=\mathbf{4 2 . 8} \%$ ) participated in four active games across two consecutive days. Each day, children participated in two 16-minute games and received verbal encouragement from an adult leader. Each game was divided into four-minute intervals alternating between LP or no LP. LP was counter-balanced across two days. Each child wore an Actigraph GT1M accelerometer. Time spent in moderate-to-vigorous PA (MVPA), vigorous PA (VPA), and sedentary behavior (SB) was determined by Freedson's MET prediction. Data were analyzed using a condition (LP or no LP) by game repeated-measures ANCOVA. Results: Children participated in MVPA $52.3 \%$ of game time across all games. There were no differences in MVPA, VPA, and SB by gender, weight status, or ethnicity. LP and no LP conditions were not different for MVPA, VPA, or SB. Conclusions: These results show no effect of LP on PA in children during active games. It may be that LP could not increase PA because the children were already exhibiting high levels of MVPA.

Keywords: Accelerometer; Obesity; Exercise; Evidence-Based Research

\section{INTRODUCTION}

Childhood obesity prevalence has increased dramatically over the past 30 years in the United States. The percentage of overweight 6 to 19 year old children and adolescents has tripled since 1980 [1]. Children who participate in regular physical activity (PA) are less likely to be obese and may be more likely to be physically active as adults [2]. Recent recommendations suggest that youth should accumulate 60 minutes or more of moderate-to-vigorous PA per day [3]. Evidence indicates that only $42 \%$ of 6 to 12 year olds, and $8 \%$ of 12 to 19 year olds, meet recommendations [4]. Thus, a need exists to identify evidence-based strategies that increase children's PA.

Group PA settings, such as physical education, recess, and out-of-school programs and clubs provide PA opportunities [5]. These settings, according to Social Cognitive Theory [6], are physical and social environments that reciprocally interact with personal factors to determine PA. Several studies have examined the social and physical environment influences on habitual child PA $[7,8]$, and how to increase PA by making changes in the physical environment [9-12]. However, few studies have examined social environmental influences during group PA settings [13].

Adults organizing PA sessions, according to Social Cognitive Theory [6], can provide direct reinforcement and vicarious experiences to increase learning and motivation for health behaviors. A particular focus of this study was the provision of vicarious experiences to increase self-efficacy. Self-efficacy, defined as a child's confidence in using their skills and capabilities to perform PA at a level to attain a desired outcome, has been associated with PA [14,15]. Increased self-efficacy can be developed vicariously through the process of observing adult and child models performing health behaviors, such as PA. In settings where groups of children engage 
in active play, one potential strategy to achieve increased self-efficacy is through adult leaders modeling PA during active game-play.

There is some evidence for the hypothesis that adult modeling influences children's PA [16,17]. For example, Sallis and colleagues (1992) examined the association between parental behavior and their fourth grade child's PA. Parental participation in PA or playing sports with their child (sons only) was a positive predictor of child PA [18]. This study suggests that parents who participate in PA with their children are more likely to have children who are physically active. Furthermore, the greater parents' reported social support the more likely their children were to engage in an hour of PA daily [19]. The parental support measure assessed participating in PA with the child, as well as encouraging the child to be active, providing transportation to be active, watching the child engage in PA, and providing verbal encouragement [20]. Although this study suggested that parental support for PA influences their child's PA, it is not conclusive that parental participation in PA with or without the children was a key variable.

Contrary to these findings, one study did not show an association between adult participation and children's moderate-to-vigorous PA [21]. This study examined the effects of parent participation on 7 - 8 years old moderate-to-vigorous PA and use of the Dance Dance Revolution video game. Parents were encouraged to participate as well as support their child's PA and the video game participation for 120 minutes per week for 10 weeks. Results showed that parental encouragement was more frequent than parental participation (5 - 6 days vs. 2 days per week). Parental encouragement and participation were not associated with child participation in moderateto-vigorous PA or Dance Dance Revolution [21].

In addition to parental influences on their children's PA, adults other than parents may be able to influence children's PA. Very few studies have examined the relationship between adult participation and child PA in children's group PA sessions. Donnelly and colleagues (2009) developed the Physical Activity Across the Curriculum (PAAC) randomized controlled trial to increase PA through teacher delivery of physically active academic lessons [22]. Observational results showed that, compared with teachers who were less active during academic PA lessons, teachers who were more active during the academic PA lessons had students who were more active as well. In contrast, another study involving preschool-aged children found that children were more than three times more likely to participate in moderate-to-vigorous PA alone during outdoor play compared to when an adult was participating [23]. This study suggested that preschool-aged children are more active without adult participation in free-play PA, whereas pre- viously discussed studies illustrated that school-age children benefit from adult participation.

Current research has provided inconclusive evidence as to whether or not adults can influence children's PA by participating in the activity. The purpose of this study was to examine the effects of adult LP compared to no adult leader participation (no LP) among children playing organized active games on their sedentary behavior, moderate-to-vigorous PA, and vigorous PA. Based on Social Cognitive Theory, and previous evidence, we hypothesized that children would be more active with adult participation compared to no adult participation.

\section{METHODS}

\subsection{Settings and Participants}

Research assistants delivered a one-week summer day camp at a Midwest University community fitness center for three-hours each day. The camp exposed children entering grades four through six $(9-11$ years old $)$ to a variety of active and non-active games, as well as nutriation education activities. Children were recruited during the summer of 2008 through community organizations and public announcements.

All children $(n=16)$ enrolled in the day camp were eligible to participate in this study, which was conducted during the third and fourth days of the camp. Informed consent was obtained from the parent or guardian along with the written assent of the child. Fourteen of the 16 children participated in the study and were included in the final sample. One child was excluded due to absence and another child was excluded due to age. This study was approved by the Institutional Review Board at the research team's university.

\subsection{Experimental Conditions}

Over the two data collection days, children participated in two 16-minute organized, active games with a 10-minute break separating the games. Each game was divided into four-minute intervals alternating between a condition of LP or no LP. The sequence of exposure to LP or no LP was counter-balanced across the two days. During LP, the roles of leaders were to model playing the games by: being active participants; being enthusiastic; making games fun for children; and keeping all children active and involved in the games. Depending on the game, leaders would chase and tag children, throw balls, do jumping jacks or other movements, take scarves, etc. One female and one male leader participated in the games during the LP condition. Both adult leaders were familiar with the game rules and had experience leading physically active games in youth. During no LP, the adult leaders stood outside the playing area and did not 
participate in game play. Verbal encouragement was controlled in both conditions (LP and no LP), such that every minute, adult leaders encouraged the children to be active following a list of verbal (e.g., good job, keep up the good work, keep going) and physical prompts (e.g., clapping)

Children participated in four organized, active games (adapted from the CATCH program) across two consecutive days. The CATCH physical education objecttives included: involvement of at least 30 minutes of daily PA, involvement in moderate-to-vigorous PA for at least $40 \%$ of total PA time, providing children with many opportunities to participate and practice skills, and providing children with a variety of enjoyable activities [24]. On day one, the games chosen were Dragon's Tail, and Hospital Tag; on day two, games were Everybody's It Dodge-ball, and Foxes, Trees, and Squirrels. Children were exposed to all four games on the camp days preceding the study to familiarize the children with the rules and expectations for the study. The games were played in a fitness facility on an aerobic class' hardwood floor. The playing area was marked off with cones, measuring $11 \times 10$ yards.

Dragon's Tail: Each child and leader tucked a tail (scarf) into the back of their waistband, illustrating that they were dragons. On "go," dragons ran/skipped through the playing area attempting to pull the tails of other dragons. When a dragon pulled another dragon's tail, he/she would say "(Name), I got your tail!" and then place the tail on the ground. When a dragon lost his/her tail, he/she would pick up his/her tail and do the five repetitions of a specified gross motor movement, such as jumping jacks, before returning to the game. Adult leaders selected different gross motor movements (i.e., situps, push-ups, frog jumps, etc.) after several minutes to keep children interested in the game.

Hospital Tag: Within the play space perimeter, there was a designated area for a "hospital". Each child was "it" and on "go," all players attempted to tag other players. The first time a player was tagged, he/she put one hand on the tagged spot. The second time tagged, a player placed his/her second hand on the tagged spot. When tagged a third time, the player went to the "hospital" and did specified gross motor movements (selected by adult leaders) before he/she could leave the hospital and re-enter the game.

Everybody's It Dodgeball: Balls were scattered around the playing area and when the leader said "go," the children grabbed a ball and threw it at anyone participating in the game. If a child was hit with a ball (below the shoulders), he/she left the playing area, and did specified gross motor movements (selected by adult leaders) before he/she was allowed back in the game. If the child caught a ball thrown at him/her, then whomever threw the ball had to perform the specified gross motor movements (i.e., jumping jacks, sit-ups, push-ups, etc.).

Foxes, Trees and Squirrels: Three plastic hoops were scattered within the play space area to represent trees. Half of the children were given scarves to tuck into the back of their waistband to represent squirrels, and children without a tail were considered foxes. On "go," foxes tried to pull the tails off the squirrels. If a fox got a tail, then the fox tucked the scarf in his/her waistband and became a squirrel, and the squirrel became a fox. The trees were safe zones where squirrels were protected from being tagged. Squirrels were allowed in the tree for up to five seconds, counting each second as an acorn (i.e., one acorn, two acorn, etc.).

\subsection{Measures}

Height and weight were measured in a private location on the first day of camp. Height was measured to the nearest $0.1 \mathrm{~cm}$ using a stadiometer (Seca Corp, Model 214 Hamburg, Germany) and weight was measured to the nearest $0.1 \mathrm{~kg}$ using an electronic scale (Seca Corp, Model 770, Hamburg, Germany) that was calibrated daily. Body mass index (BMI) was calculated from these measurements and children were classified according to the age- and sex-specific CDC growth charts for normal weight (5th to $<85$ th percentile) and overweight/obese ( $\geq 85$ th percentile) [25]. Adiposity was directly measured using Dual-Energy X-Ray Absorptiometry (DEXA) and children were categorized as normal weight $(<85$ th percentile) or overweight/obese ( $\geq 85$ th percentile) according to body fat percentile curves adjusted for age and gender [26].

Physical activity levels were objectively measured using the Actigraph GT1M accelerometer (Shalimar, FL). The Actigraph GT1M accelerometer has been found to be a valid and reliable measure of PA in youth [27]. Children wore the accelerometer around their waist at the right hip, secured by an adjustable elastic belt, for the total duration (three hours) each day of the camp. Activity counts were collected using 15 -second epochs. Sedentary behavior was defined as less than 200 counts per minute [28]. Time spent in light $(200$ counts to $<4$ METS), moderate PA ( 4 to $<7$ METS), vigorous PA $(\geq 7$ METS), and moderate-to-vigorous PA ( $\geq 4$ METS) was determined by Freedson's MET prediction equation [29]. The cutpoints chosen for the intensity levels are commonly used in children [4,30].

Parents completed a brief survey prior to their child's participation in the camp. The parent survey captured demographic information such as age, gender, socioeconomic status, ethnicity, and child PA. Child PA was assessed prior to the week-long camp using the PACE + PA measure [31]. Parental report of child PA has been shown to more accurately assess child PA than child 
self-report in this age group [32]. Children were categorized as meeting guidelines if they performed moderate-to-vigorous PA five or more days per week for at least 60 minutes.

\subsection{Data Analysis}

We conducted within-subjects ANCOVAs examining the effect of condition (LP or no LP) on PA and SB, while controlling for the type of game and the order of receiving the counter-balanced condition. Effect sizes (ES) were also calculated to assess the practical significance of the LP in relation to the no LP condition. Effect size was the difference between the two group means, divided by the standard deviation. To aid in interpretation of the results, we report descriptive data as percent time in each activity intensity, during each condition. All data were analyzed using SPSS Version 14.0. All tests were conducted at $\mathrm{p}<0.05$.

\section{RESULTS}

Table 1 describes the demographic and anthropometric characteristics of the participants. Of the 14 participants, six were male $(42.9 \%)$, seven were white $(50 \%)$, six were overweight/obese according to DEXA (42.9\%), and nine met PA guidelines (64.3\%) based on the PACE + PA measure [31].

Children participated in moderate-to-vigorous PA $52.2 \%(\mathrm{SE}=0.042)$ of game time across all games, $53.1 \%(\mathrm{SE}=0.042)$ during no LP and $51.4 \%(\mathrm{SE}=$ 0.043 ) during LP. Percent of time spent in vigorous PA during $\mathrm{LP}$ and no LP was $20.8 \%(\mathrm{SE}=0.032)$ and $19.6 \%$ $(\mathrm{SE}=0.032)$, respectively. Percent of time in sedentary behavior, during LP and no LP was $14.5 \%(\mathrm{SE}=0.032)$ and $15.5 \%(\mathrm{SE}=0.030)$, respectively. Leader participation and no LP conditions were not significantly different for moderate-to-vigorous PA $(\mathrm{p}=0.40, \mathrm{ES}=-0.02)$, vigorous $\mathrm{PA}(\mathrm{p}=0.53, \mathrm{ES}=0.01)$, or sedentary behavior $(p=0.59, E S=-0.01)$. There were also no differences in moderate-to-vigorous $\mathrm{PA}$, vigorous $\mathrm{PA}$ and sedentary behavior by gender $(p>0.05)$, weight status $(p>0.05)$, or ethnicity $(p>0.05)$. Means and standard errors for percent time in PA and sedentary behavior are presented in Table 2.

\section{DISCUSSION}

The primary aim of this study was to examine the impact of LP or no LP during organized, active games on children's PA levels. Results showed no effect of LP on PA in children during active games. It may be that LP did not increase PA because the children were already exhibiting high levels of moderate-to-vigorous PA during game play. Children in both LP and no LP participated in moderate-to-vigorous PA for more than $50 \%$ of
Table 1. Demographic characteristics $(n=14)$ for children enrolled in study.

\begin{tabular}{|c|c|c|}
\hline Characteristic & $\mathrm{N}$ & $\begin{array}{l}\text { Percent or } \\
\text { mean (SD) }\end{array}$ \\
\hline \multicolumn{3}{|l|}{ Gender } \\
\hline Male & 6 & $42.9 \%$ \\
\hline Female & 8 & $57.1 \%$ \\
\hline Age & 14 & $10.9(0.68)$ \\
\hline \multicolumn{3}{|l|}{ Grade level } \\
\hline 4 & 3 & $21.4 \%$ \\
\hline 5 & 7 & $50.0 \%$ \\
\hline 6 & 4 & $28.6 \%$ \\
\hline \multicolumn{3}{|l|}{ Ethnicity } \\
\hline White & 7 & $50.0 \%$ \\
\hline Non-white & 7 & $50.0 \%$ \\
\hline \multicolumn{3}{|l|}{ Weight status (BMI) } \\
\hline$<85$ th percentile & 11 & $78.6 \%$ \\
\hline$\geq 85$ th percentile & 3 & $21.4 \%$ \\
\hline \multicolumn{3}{|l|}{ Weight status (\% Body Fat) } \\
\hline$<85$ th percentile & 8 & $57.1 \%$ \\
\hline$\geq 85$ th percentile & 6 & $42.9 \%$ \\
\hline \multicolumn{3}{|c|}{ Meeting PA guidelines $(\mathrm{PACE}+\mathrm{PA})$} \\
\hline Yes & 9 & $64.3 \%$ \\
\hline No & 5 & $35.7 \%$ \\
\hline \multicolumn{3}{|l|}{ Subsidized school lunch } \\
\hline Yes & 2 & $14.3 \%$ \\
\hline No & 12 & $85.7 \%$ \\
\hline \multicolumn{3}{|l|}{ Mother's Education } \\
\hline High school & 0 & $0 \%$ \\
\hline Some college & 6 & $42.9 \%$ \\
\hline$\geq$ Bachelor's degree & 8 & $57.1 \%$ \\
\hline Father's education & & $7.1 \%$ \\
\hline High school & 1 & $7.1 \%$ \\
\hline Some college & 3 & $21.4 \%$ \\
\hline$\geq$ Bachelor's degree & 10 & $71.4 \%$ \\
\hline
\end{tabular}

Table 2. Means (SE) of sedentary behavior and physical activity expressed as percent time.

\begin{tabular}{ccccc}
\hline Measure & $\begin{array}{c}\text { No leader } \\
\text { participation } \\
\text { mean\% (SE) }\end{array}$ & $\begin{array}{c}\text { Leader } \\
\text { participation } \\
\text { mean\%(SE) }\end{array}$ & f-value & p-value \\
\hline Sedentary & $15.5(0.030)$ & $14.5(0.032)$ & 0.30 & 0.59 \\
Light PA & $31.4(0.021)$ & $34.1(0.025)$ & 2.29 & 0.15 \\
$\begin{array}{c}\text { Moderate } \\
\text { PA }\end{array}$ & $33.4(0.019)$ & $30.6(0.020)$ & 3.63 & 0.08 \\
$\begin{array}{c}\text { Vigorous } \\
\text { PA }\end{array}$ & $19.6(0.032)$ & $20.8(0.032)$ & 0.42 & 0.53 \\
MVPA & $53.1(0.042)$ & $51.4(0.043)$ & 0.76 & 0.40 \\
\hline
\end{tabular}


the time during all game-play, exceeding the $\mathrm{CATCH}$ recommendations for PA during game-play [24].

Based on the Social Cognitive Theory, we hypothesized that children's level of PA would be higher during LP compared to the no LP condition due to modeling. However, our results did not support this hypothesis. Most research on the Social Cognitive Theory constructs and children's PA examines parent or peer social support and modeling of PA on individual children's habitual PA levels (not during specific organized active games). For example, Prochaska and colleagues (2002) examined children's self-reported peer and parent PA social support on their habitual PA levels (meeting PA recommendations or not). Results showed that parent and peer support for child PA was associated with increased child self-reported PA, but not for objectively measured child PA. Similar, Trost and colleagues (2003), also reported that parent self-report support for child PA was associated with increased child habitual PA. However, our study was very different, in that we examined a group of children engaged in organized active games with leaders participating during game play.

To our knowledge, this is the first study to examine adult LP and objective child PA in organized active game sessions. As previously mentioned, children in both conditions (LP and no LP) exhibited high levels of moderate-to-vigorous PA during game play. It may be that for games or settings with activity levels less than $40 \%$ of the total time, LP could have been effective at increasing children's moderate-to-vigorous PA levels. For instance, schools have long been regarded as ideal settings for the promotion of PA, as that's where children spend a majority of their time. However, children are not meeting the CATCH recommendations of engaging in $40 \%$ moderate-to-vigorous PA during PA sessions, such as recess [33,34]. Although, LP did not increase children's moderate-to-vigorous PA or decrease sedentary behavior in our study, future studies could examine the effect of LP on children's PA during recess or free play in children that do not engage in moderate-to-vigorous PA for at least $40 \%$ of the time.

Coleman and colleagues (2008) examined children's PA levels and leader behavior during organized and free play PA sessions, in the after-school environment. Children's PA and leader behavior was measured by systematic observation. Overall, children exhibited greater levels of moderate-to-vigorous PA in free play compared to organized PA sessions. However, there was greater encouragement (verbal and physical) during organized PA as compared to free play PA [35]. These data suggests that children are most active during free play, and most free play occurs with no LP. To relate these results to our study, it is possible that adult LP during organized games is common and the continuous verbal encouragement during LP and no LP in our study was enough to maintain high PA levels in the children.

Providing vicarious experiences, such as modeling, to increase motivation is a strategy teachers could use to promote PA. Cullen and colleagues (2001) examined modeling of fruit and vegetable consumption by parents and peers and found that modeling by both parents and peers is correlated with children's fruit and vegetable intake [36]. Although this study was conducted via survey instruments rather than direct observation of children and peers/parents eating together, it presents an argument that modeling increases healthy behaviors. Similarly, Hendy \& Raudenbush (2000) observed three methods to encourage food acceptance by preschool children: silent teacher modeling; enthusiastic teacher modeling; and enthusiastic teacher modeling plus a competing peer model. Results found that a silent teacher model was ineffective in children's eating of modeled foods; however enthusiastic teacher modeling was successful in children's new food acceptance [37]. Conversely, when a competing peer was present, the enthusiastic teacher model was no longer successful in children's new food acceptance. Comparing our results to Hendy \& Raudenbush (2000), there are several similarities. Since children were introduced to all four games prior to our study, the "newness" or the excitement of the games may have diminished any potential modeling effect. Perhaps because our adult models were silent other than verbal encouragement every minute, more verbal cues were necessary to increase PA during LP. Or it could be that the peer models were more effective than teacher models in increasing PA during LP since there were not PA differences during LP and no LP.

The verbal encouragement provided under both conditions (LP and No LP) may have negated the effect of LP. Verbal encouragement was used to imitate a typical organized game session such as in a PA class or an organized youth sport, where leaders typically would not remain silent during the entire game play. It is possible that the verbal encouragement provided each minute was sufficient by itself to maintain the activity levels of the children playing the game, thus a ceiling effect occurred and LP (modeling game play and being active participants) was unable to increase the already high levels of PA exhibited. A follow-up study should include the effects of verbal encouragement on PA levels.

\subsection{Limitations}

There are important limitations to this study. First, the influence of LP on PA may be moderated by factors not examined in this study, such as gender and weight status. Second, two different games were played each day. Therefore, it is unknown whether playing the same two 
games each day would have similar results. Third, there could have been carryover from previous experiences, whether on the same day, different day, or particularly from the previous four-minute interval that was not taken into account by the counterbalanced design. Maybe intermittent LP was all it took to ensure adequate moderate-to-vigorous PA. Fourth, a small sample size may have limited the testing of interactions; however, all children enrolled in the camp participated in the study. Last, children did not complete questionnaires about their self-efficacy and enjoyment of the games, thus we are unsure if children prefer active games with LP or no LP.

\subsection{Strengths}

An important strength of this study was that PA was measured objectively using accelerometers. To our knowledge, this is the first study to objectively measure PA in children to assess the impact of LP. In addition, PA was assessed using 15 -second epochs, which has been shown to be a more accurate sampling method to distinguish VPA compared to 30-second epochs [38]. Lastly, study design, including counter-balancing LP across two days and the use of evidence-based games are important strengths.

\section{CONCLUSION}

Findings from this study indicate that adult LP does not impact PA in children in this context. Perhaps LP was not able to increase PA due to the children's strong level of moderate-to-vigorous PA during game play. However, this was only one small study, more studies are necessary to determine whether LP can increase children's PA. Future studies should examine whether LP can increase the quality and/or quantity of PA in children during other PA contexts, such as free-play and in children in other age groups and weight status categories.

\section{ACKNOWLEDGEMENTS}

We thank Joey Mims, Sara Corn, and Tyler Wiegert for their assistance with the study. We also thank the parents for allowing their children to participate in the study and the children for their participation.

\section{REFERENCES}

[1] Ogden, C.L., Carroll, M.D., Curtin, L.R., Lam, M.M. and Flegal, K.M (2010) Prevalence of high body mass index in US children and adolescents, 2007-2008. The Journal of the American Medical Association, 303, 242-249. doi:10.1001/jama.2009.2012

[2] Nelson, M.C., Gordon-Larsen, P., North, K.E. and Adair, L.S. (2006) Body mass index gain, fast food, and physical activity: Effects of shared environments over time. Obe- sity, 14, 701-709. doi:10.1038/oby.2006.80

[3] US Department of Health and Human Services (2008) Physical activity guidelines for Americans. http://www.health.gov/PAguidelines/pdf/paguide.pdf

[4] Troiano, R.P., Berrigan, D., Dodd, K.W., Masse, L.C., Tilert, T. and McDowell, M. (2008) Physical activity in the United States measured by accelerometer. Medicine and Science in Sports and Exercise, 40, 181-188.

[5] Dzewaltowski, D.A. (2008) Community out-of-school physical activity promotion. In: Smith, A.L. and Biddle, S.J.H., Eds., Youth Physical Activity and Sedentary Behavior: Challenges and Salutations, Human Kinetics, Champaign, 377-401.

[6] Bandura, A. (1986) Social foundations of thought and action: A social cognitive theory. Prentice Hill, Englewood Cliffs.

[7] Patnode, C.D., Lytle, L.A., Erickson, D.J., Sirard, J.R., Barr-Anderson, D. and Story, M. (2010) The relative influence of demographic, individual, social, and environmental factors on physical activity among boys and girls. International Journal of Behavioral Nutrition and Physical Activity, 3, 79. doi:10.1186/1479-5868-7-79

[8] Sallis, J.F., Taylor, W.C., Dowda, M., Freedson, P.S. and Pate, R.R. (2002) Correlates of vigorous physical activity for children in grades 1 through 12: Comparing parentreported and objectively measured physical activity. $\mathrm{Pe}$ diatric Exercise Science, 14, 30-44.

[9] Brink, L.A., Nigg, C.R., Lampe, S.M., Kingston, B.A., Mootz, A.L. and van Vliet, W. (2010) Influence of schoolyard renovations on children's physical activity: The learning landscapes program. American Journal of Public Health, 100, 1672-1678. doi:10.2105/AJPH.2009.178939

[10] Ridgers, N.D., Fairclough, S.J and Stratton, G. (2010) Twelve-month effects of a playground intervention on children's morning and lunchtime recess physical activity levels. Journal of Physical Activity \& Health, 7, 137-175.

[11] Ridgers, N.D., Stratton, G., Fairclough, S.J. and Twisk, J.W. (2007) Children's physical activity levels during school recess: A quasi-experimental intervention study. International Journal of Behavioral Nutrition \& Physical Activity, 4, 19-28. doi:10.1186/1479-5868-4-19

[12] Verstraete, S.J., Cardon, G.M., De Clercq, D.L. and De Bourgdeaudjuih, I.M. (2006) Increasing children's physical activity levels during recess periods in elementary schools: The effects of providing game equipment. European Journal of Public Health, 16, 415-419. doi:10.1093/eurpub/ckl008

[13] McKenzie, T.L., Crespo, N.C., Baquero, B. and Elder, J.P. (2010) Leisure-time physical activity in elementary schools: Analysis of contextual conditions. Journal of School Health, 80, 470-477. doi:10.1111/j.1746-1561.2010.00530.x

[14] Salmon, J., Brown, H. and Hume, C. (2009) Effects of strategies to promote children's physical activity on potential mediators. International Journal of Obesity, 33, S66-S73. doi:10.1038/ijo.2009.21

[15] Van Der Horst, K., Paw, M.J., Twisk, J. W. and Van Mechelen, W. (2007) A brief review on correlates of physical activity and sedentariness in youth. Medicine and Science 
in Sports and Exercise, 39, 1241-1250. doi:10.1249/mss.0b013e318059bf35

[16] Davison, K.K. and Jago, R. (2009) Change in parent and peer support across ages 9 to $15 \mathrm{yr}$ and adolescent girls' physical activity. Medicine and Science in Sports and EXercise, 41, 1816-1825.

doi:10.1249/MSS.0b013e3181a278e2

[17] Gattshall, M.L., Shoup, J.A., Marshall, J.A., Crane, L.A. and Estabrooks, P.A. (2008) Validation of a survey instrument to assess home environments for physical activity and healthy eating in overweight children. International Journal of Behavioral Nutrition and Physical Activity, 5, 1-13. doi:10.1186/1479-5868-5-3

[18] Sallis, J.F., Alcaraz, J.E., McKenzie, T.L., Hovell, M.F., Kolody, B. and Nader, P.R. (1992) Parental behavior in relation to physical activity and fitness in 9-year-old children. American Journal of Diseases of Children, 146, 13831388.

[19] Zecevic, C.A., Tremblay, L., Lovsin, T. and Lariviere M. (2010) Parental influence on young children's physical activity. International Journal of Pediatrics, 2010, 9p. doi: $10.1155 / 2010 / 468526$

[20] Trost, S.G., Sallis, J.F., Pate, R.R., Freedson, P.S., Taylor, W.C. and Dowda, M. (2003) Evaluation a model of parental influence on youth physical activity. American Journal of Preventive Medicine, 25, 277-282. doi:10.1016/S0749-3797(03)00217-4

[21] Paez, S., Maloney, A., Kelsey, K., Wiesen, C. and Rosenberg, A. (2009) Parental and environmental factors associated with physical activity among children participating in an active video game. Pediatric Physical Therapy, 21, 245-253. doi:10.1097/PEP.0b013e3181b13a82

[22] Donnelly, J.E., Greene, J.L., Gibson, C.A., Smith, B.K., Washburn, R.A., Sullivan, D.K., et al. (2009) Physical activity across the curriculum (PAAC): A randomized controlled trial to promote physical activity and diminish overweight and obesity in elementary school children. Preventive Medicine, 49, 336-341. doi:10.1016/j.ypmed.2009.07.022

[23] Brown, W.H., Pfeiffer, K.A., McIver, K.L., Dowda, M., Addy, C.L. and Pate, R.R. (2009) Social and environment factors associated with preschoolers' nonsedentary physical activity. Child Development, 80, 45-58. doi:10.1111/j.1467-8624.2008.01245.x

[24] McKenzie, T.L., Strikmiller, P.K., Stone, E.J., Woods, S.E., Ehlinger, S.S., Romero, K.A., et al. (1994) CATCH: Physical activity process evaluation in a multicenter trial. Health Education Quarterly, 2, S73-S89.

[25] Kuczmarski, R.J., Ogden, C.L., Grummer-Strawn, L.M., Flegal, K.M., Guo, S.S., Wei, R., et al. (2000) CDC growth charts: United States. Advance Data, 314, 1-27.

[26] Taylor, R.W., Jones, I.E., Williams, S.M. and Goulding, A. (2002) Body fat percentages measured by dual-energy Xray absorptiometry corresponding to recently recommended body mass index cutoffs for overweight and obesity in children and adolescents aged $3-18$ y. The American Journal of Clinical Nutrition, 76, 1416-1421.

[27] Trost, S.G., McIver, K.L. and Pate, R.R. (2005) Conducting accelerometer-based activity assessments in fieldbased research. Medicine and Science in Sports and EXercise, 37, S531-43. doi:10.1249/01.mss.0000185657.86065.98

[28] Mattocks, C., Leary, S., Ness, A., Deere, K., Saunders, J., Kirkby, J., et al. (2007) Intraindividual variation of objectively measured physical activity in children. Medicine and Science in Sports and Exercise, 39, 622-629. doi:10.1249/mss.0b013e318030631b

[29] Freedson, P., Pober, D. and Janz, K.F. (2005) Calibration of accelerometer output for children. Medicine and Science in Sports and Exercise, 37, S523-S30.

[30] Foster, K.E., Behrens, T.K., Jager, A.L., Dzewaltowski, D.A. (2010) Effect of elimination games on physical activity and psychosocial responses in children. Journal of Physical Activity and Health, 7, 475-483.

[31] Prochaska, J.J., Sallis, J.F. and Long, B. (2001). A physiccal activity screening measure for use with adolescents in primary care. Archives of Pediatrics \& Adolescent Medicine, 155, 554-559.

[32] Sithole, F. and Veugelers, P.J. (2008) Parent and child reports of children's activity. Health Reports (Statistics Canada), 19, 19-24.

[33] Mota, J., Silva, P., Santos, M.P., Ribeiro, J.C., Oliveira, J. and Duarte, J.A. (2005) Physical activity and school recess time: Differences between the sexes and the relationship between children's physical activity and habitual physical activity. Journal of Sports Sciences, 23, 269-275. doi:10.1080/02640410410001730124

[34] Stratton, G., Ridgers, N.D., Fairclough, S.J. and Richardson, D.J. (2007) Physical activity levels of normal-weight ad overweight girls and boys during primary school recess. Obesity, 15, 1513-1519. doi:10.1038/oby.2007.179

[35] Coleman, K.J., Geller, K.S., Rosenkranz, R.R. and Dzewaltowski, D.A. (2008) Physical activity and health eating in the after-school environment. Journal of School Health, 78, 633-640. doi:10.1111/j.1746-1561.2008.00359.x

[36] Cullen, K.W. Baranowski, T., Rittenberry, L., Cosart, C., Hebert, D. and de Moor, C. (2001) Child-reported family and peer influences on fruit, juice and vegetable consumption: Reliability and validity of measures. Health Education Research, 16, 187-200. doi:10.1093/her/16.2.187

[37] Hendy, H.M. and Raudenbush, B. (2000) Effectiveness of teacher modeling to encourage food acceptance in preschool children. Appetite, 34, 61-76. doi:10.1006/appe.1999.0286

[38] Baquet, G., Stratton, G., Van Praagh, E. and Berthoin, S. (2007) Improving physical activity assessment in prepubertal children with high-frequency accelerometry monitoring: A methodological issue. Preventive Medicine, 44, 143-147. doi:10.1016/j.ypmed.2006.10.004 